\title{
II Diretrizes da Sociedade Brasileira de Cardiologia Sobre Teste Ergométrico
}

\author{
Coordenador Geral e Editor \\ Jadelson Andrade (BA) \\ Comissão de redação \\ Fábio Sândoli de Brito (SP) \\ Fábio Vilas-Boas (BA) \\ Iran Castro(RS) \\ Japy Angelin de Oliveira (SP) \\ Jorge Ilha Guimarães (RS) \\ Ricardo Stein (RS) \\ Correspondência: \\ Departamento de Ergometria e Reabilitação Cardíaca da Sociedade Brasileira de Cardiologia \\ Rua Ipú,32-Botafogo-22281-040-Rio de Janeiro,RJ-E-mail: sbcgeral@cardiol.br \\ Grupos de trabalho \\ Introdução \\ Jadelson Andrade (BA) \\ Fábio Sândoli de Brito (SP) \\ Indicações e Contra-Indicações do Teste Ergométrico \\ Álvaro Bellini (SP) \\ Antônio Felipe Simão(SC) \\ Artur Herdy (SC) \\ Fábio Vilas-Boas (BA) \\ Japy Angelin Filho (SP) \\ Paulo Toscano (PE) \\ Ricardo Coutinho(PE) \\ Ricardo Stein(RS) \\ Aspectos Legais da Prática Ergométrica \\ Augusto Heitor Xavier de Brito (RJ) \\ Heloísa Borges (MG) \\ Luís Eduardo Mastrocolla (SP) \\ Nabyl Ghorayeb (SP)

\section{Metodologia} \\ Ricardo Vivacqua (RJ) \\ Maurício Nunes (BA) \\ Milton Godoy (SP) \\ Salvador Serra (RJ)
}


Escolha dos Sistemas de Registro e Monitorização

Ricardo Stein (RS)

Roberto Alfieri (SP)

\title{
Aplicações Clínicas do Teste Ergométrico
}

Jorge Pinto Ribeiro (RS)

Jorge Ilha Guimarães (RS)

\author{
Respostas Clínicas e Eletrocardiográficas Frente ao Esforço \\ Iran Castro (RS) \\ Salvador Ramos (RS)
}

\section{TESTEERGOMÉTRICOEMASSOCIAÇÃOCOMOUTROSMÉTODOS}

\author{
Ecocardiografia de Estresse \\ Washington Araújo (RJ) \\ Cintilografia Miocárdica \\ José Nolasco (AL) \\ Luís Eduardo Mastrocolla (SP) \\ Romeu Sérgio Meneghello (SP) \\ William Chalela(SP) \\ Ergoespirometria \\ Claudio Gil S. Araújo(RJ) \\ Fábio Vilas-Boas (BA) \\ Paulo Yazbeck (SP) \\ Elaboração do Laudo do Teste Ergométrico \\ Claudio Gil Soares Araújo (RJ) \\ RicardoStein (RS) \\ Colaboração \\ Marianna Andrade (BA)
}




\begin{tabular}{|ll|}
\hline \multicolumn{1}{|c|}{ Graus de recomendação e níveis de evidências utilizados neste documento } \\
\hline Graus & Definição \\
\hline A) Definitivamente recomendada & A realização do exame é sempre aceitável e segura, definitivamente útil, de eficácia e efetividade comprovadas \\
B) Recomendável & A realização do exame é aceitável e segura, clinicamente útil, mas ainda não há indicação absoluta para sua realização \\
B1) Evidência muito boa & Considerado exame de escolha \\
B2) Evidência razoável & Considerado exame opcional ou alternativo \\
C) Não recomendável & O exame não tem utilidade clínica ou pode até ser prejudicial \\
\hline Níveis de evidência & Definição \\
\hline 1 & Dados derivados de múltiplos estudos envolvendo grande número de pacientes \\
2 & Dados derivados de um número limitado de estudos que incluíram pequeno número de pacientes ou de análise cuida- \\
3 & dosa de estudos ou registros observacionais \\
\hline
\end{tabular}

\section{Introdução}

Desde que foi introduzido no Brasil em 1972, a partir do pioneirismo dos professores Josef Feher e Helio Magalhães, o TE experimentou extraordinário crescimento na sua aplicação. Como importante método de diagnóstico, passou a ser utilizado na rotina de diversos serviços em todo o país. A partir de 1976, surgiram os primeiros trabalhos científicos que foram apresentados como temas livres nos congressos da SBC, seguindo-se publicações nos Arquivos Brasileiros de Cardiologia. Em 1978 o professor Gilberto Marcondes e cols. publicaram o primeiro livro texto sobre ergometria no país, ao qual se seguiram diversos outros, contribuindo de forma significativa para divulgação do método entre os cardiologistas brasileiros. A formação do grupo de estudos em ergometria e reabilitação e sua posterior evolução para o Departamento de Ergometria e Reabilitação Cardíaca, com seu congresso anual, configurou-se em marco relevante para consolidação definitiva do método em nosso meio. Em 1994, realizou-se na cidade de Florianópolis, sob a coordenação de Luís Eduardo Mastrocola, o Consenso Nacional de Ergometria ${ }^{1}$, publicado em agosto/1995 nos Arquivos Brasileiros de Cardiologia. Em novembro de 2000, em Recife, sob a coordenação de Jadelson Andrade, promoveu-se a revisão e atualização do Consenso de 1995, surgindo então as II Diretrizes do DERC/SBC (2001).

Além de atualização dos dados, as atuais diretrizes receberam nova formatação, obedecendo aos princípios da SBC, bem como ao modelo dos consensos internacionais. Objetivou-se, portanto, apresentar os dados com a maior abrangência possível, respaldados por graus de recomendação e níveis de evidências, tornando mais fácil e segura a utilização e consulta.

\section{I - Indicações e contra-indicações}

O TE tem por objetivo submeter o paciente a estresse físico programado e personalizado, com finalidade de avaliar a resposta clínica, hemodinâmica, eletrocardiográfica e metabólica ao esforço. Essa avaliação possibilita ao médico assistente: detecção de isquemia miocárdica, arritmias cardíacas e distúrbios hemodinâmicos esforço-induzidos; avaliação da capacidade funcional; avaliação diagnóstica e prognóstica das doenças cardiovasculares; prescrição de exercícios; avaliação objetiva dos resultados de intervenções terapêuticas; demonstração ao paciente e familiares de suas reais condições físicas e perícia médica.

\section{I.1 - Indicações gerais}

Referem-se às situações em que o TE deve ser realizado por se mostrar de grande utilidade no estabelecimento do diagnóstico e orientação das condutas a serem adotadas, participando especialmente no processo de prevenção primária e secundária da DAC obstrutiva ${ }^{2-5}$.

\section{I.2 - Indicações em grupos especiais}

Considerando-se o TE um exame de baixo custo, fácil execução e alta reprodutibilidade e concebendo a realidade social de vários municípios do país, o mesmo poderá ter indicação ainda mais abrangente na prática clínica do que aquelas que são formalmente indicadas nessas diretrizes.

\section{I.2.1 - Na doença arterial coronariana}

GrauA Avaliação de homens ou mulheres com dor torácica típica (nível 1)

Avaliação pós-IAM em evolução precoce e tardia, não complicada (nível 1)

DAC crônica com modificações no quadro clínico e/ou do ECG, desde que estáveis (nível 1)

Grau B1 Pré-ATC (nível 1) Précirurgiade revascularizaçãomiocárdica(nível 1) 
Estratificação de risco de dor torácica na sala de emergência, com protocolos específicos (nível 2) Avaliação seriada de pacientes com DAC em programas de reabilitação cardiovascular (nível2) Avaliação de indivíduos assintomáticos com mais de 2 fatores de risco (nível 2)

Avaliação de terapêutica farmacológica (nível 2)

Grau B2 Avaliação após-ATC coronária (nível 2)

Avaliação após cirurgia de revascularização miocárdica (nível 2)

Avaliação prognóstica e evolutiva de DAC, anual, de acordo com a condição clínica (nível 2) Investigação de alterações de repolarização ventricular no ECG de repouso (nível 2)

Complementação de outros métodos que tenham evidenciado suspeita de DAC (nível 2)

Avaliação de risco em cirurgia não cardíaca, em pacientes com fator de risco cardiovascular (nível2) Perícia médica: pesquisa de DAC obstrutiva para fins trabalhistas ou de seguro (nível 3)

GrauC Diagnóstico de DAC em pacientes com BRE, WPW ou ritmo de MP (nível 2)

Angina instável progressiva ou de repouso, não estabilizada (nível 3)

IAM em evolução ou com complicações (nível 3) Lesão significativa de tronco de coronária esquerda ou equivalente conhecida (nível 2)

As indicações para a utilização dos métodos diagnósticos, bem como o valor prognóstico de seus resultados na DAC têm sido analisados de forma mais embasada em evidências. Assim, as implicações na probabilidade pré-teste (prevalência) e na análise do valor preditivo dos resultados têm contribuído para uma otimização no manejo prático dos mais diferentes tipos de pacientes.

\section{I.2.1.1 - Probabilidade pré-teste de DAC}

A análise pré-teste é fundamental para a interpretação do TE. Para tanto é necessário conhecer a história clínica, fatores de risco, sintomas, especialmente dor torácica ${ }^{6,7}$, bem como fazer um exame físico sumário. Os dados devem sempre ser analisados em função da idade e sexo. A experiência clínica do executor também faz parte da avaliação pré-teste, podendo auxiliar na acurácia diagnóstica do método.

Todos os parâmetros citados fazem parte da "Análise Bayesiana" da probabilidade que pode ser resumida em: “a probabilidade de um indivíduo ter a doença é igual à probabilidade pré-teste desse indivíduo versus o índice de probabilidade do teste ser positivo". Este índice depende de características peculiares do teste, tais como sensibilidade e especificidade.

\section{I.2.1.2 - Sensibilidade, especificidade e valor preditivo}

A maioria dos estudos realizados ${ }^{8-11}$ demonstra sensibilidade entre 50 e $72 \%$ (média de $67 \%$ ) e especificidade entre 69 e 74\% (média de 71\%). É importante, no entanto, ressaltar as limitações desses valores uma vez que o padrão-ouro de comparação é a cineangiocoronariografia que analisa apenas anatomia da árvore arterial coronariana. É conhecimento vigente que estágios iniciais de DAC podem determinar disfunção endotelial e desencadear respostas anormais da vasculatura coronariana, mesmo na ausência de doença obstrutiva. Outra dificuldade é a grande diversidade das populações estudadas, nem sempre superponíveis ${ }^{12}$.

O valor preditivo do TEestá diretamente relacionado à prevalência da doença na população estudada ${ }^{13-15}$ (tab. I). Caso a prevalência para DAC seja de 5\%, com sensibilidade de $50 \%$ e especificidade de $90 \%$, o valor preditivo para um TE positivo para isquemia será apenas de $21 \%$. No entanto, se a prevalência de DAC for de $50 \%$, em condições iguais de sensibilidade e especificidade, o valor preditivo positivo passará para $83 \%$.

\section{I.2.1.3 - Interpretação do TE na DAC}

Para uma correta indicação e interpretação do TE, será necessário conhecer a probabilidade pré-teste de DAC, a sensibilidade e especificidade e, principalmente, a prevalência de DAC na população estudada. Com esses elementos, pode-se indicar corretamente o TE bem como dimensionar o real valor dos seus resultados.

\section{I.2.2 - Indicações de TE em indivíduos assinto- máticos ou atletas}

Grau A Avaliação de indivíduos com história familiar de DAC precoce ou morte súbita (nível 2)

Grau B1 Avaliação de candidatos a programas de exercício (homem $>40$ anos e mulher >50 anos) (nível 3) Avaliação de indivíduos com ocupações especiais responsáveis pela vida de outros (nível 3) Avaliação de candidatos a programas de exer-

\begin{tabular}{|c|c|c|c|c|c|}
\hline \multicolumn{6}{|c|}{ Tabela I - Prevalência da doença versus valor preditivo } \\
\hline Preva & $\begin{array}{l}\text { ência } \mathrm{N}^{\circ} \text { de } \\
\text { Pacientes }\end{array}$ & $\begin{array}{l}\text { Sensibilidade } \\
\text { Especificidade }\end{array}$ & $\begin{array}{c}\mathrm{TE} \\
\text { positivo }\end{array}$ & $\begin{array}{c}\mathrm{TE} \\
\text { negativo }\end{array}$ & $\begin{array}{c}\text { VPP no } \\
\text { TE positivo }\end{array}$ \\
\hline \multirow[t]{2}{*}{$5 \%$} & 500 com DAC & $\begin{array}{c}50 \% \\
\text { sensibilidade }\end{array}$ & $250(\mathrm{VP})$ & $250(\mathrm{FN})$ & $250 / 250$ \\
\hline & 9500 sem DAC & $\begin{array}{l}90 \% \\
\text { especificidade }\end{array}$ & $950(\mathrm{FP})$ & $8550(\mathrm{VN})$ & $+850=21 \%$ \\
\hline \multirow[t]{2}{*}{$50 \%$} & 5000 com DAC & $\begin{array}{c}50 \% \\
\text { sensibilidade }\end{array}$ & $2500(\mathrm{VP})$ & $2500(\mathrm{FN})$ & $2500 / 2500$ \\
\hline & 5000 sem DAC & $\begin{array}{c}90 \% \\
\text { especificidade }\end{array}$ & $500(\mathrm{FP})$ & $4500(\mathrm{VN})$ & $+500=83 \%$ \\
\hline
\end{tabular}

VP- Verdadeiro positivo; FP- Falso positivo; FN- Falso negativo; VNVerdadeiro negativo; VPP- Valor preditivo positivo 
cício com mais de uma resposta positiva no PAR-Q (nível 3)

Grau B2 Avaliação inicial de atletas de competição(nível 2) Avaliação funcional seriada de atletas, para ajustes de prescrição do exercício (nível 2)

Deve-se ressaltar que os objetivos principais nesta população são ${ }^{16-18}$ : avaliação funcional; motivação para mudança de hábitos de vida; programação de exercícios físicos; complementação de avaliação clínica rotineira ${ }^{19}$ e identificação de indivíduos sob risco de morte súbita na atividade desportiva.

Dada a baixa prevalência de DAC nesse grupo, verificase uma elevada incidência de resultados "falso-positivos". O valor preditivo para incidência de eventos futuros (angina, IAM e morte) é pequeno, devendo, em casos selecionados, haver investigação complementar. Portanto, não está recomendada a aplicação indiscriminada do TE, como elemento de apoio ao diagnóstico nesta população.

\section{I.2.3 - Indicações de TE na hipertensão arterial sistêmica}

Sendo a HAS um fator de risco para DAC, o TE permite confirmar o diagnóstico em pacientes com sintomas sugestivos de isquemia miocárdica. Entretanto, em hipertensos com alterações no ECG de repouso compatíveis com SVE, o valor preditivo positivo do teste pode ser prejudicado devido a uma maior incidência de infradesnível do segmento ST, mesmo na ausência de DAC obstrutiva. Essas alterações podem no entanto, corresponder à isquemia secundária, à desproporção entre oferta e demanda de oxigênio no miocárdio sobrecarregado, ou ainda, representar teste "falso-positivo". Assim, em pacientes com HAS e ARV secundária poderá ser desejável a complementação diagnóstica com métodos de imagem.

Por outro lado, o alto valor preditivo negativo nessa população torna o exame ideal para rastreamento inicial de DAC, uma vez que na presença de teste inicial negativo, a probabilidade da existência de DAC torna-se reduzida. Deve-se ressaltar que quando o exame é indicado para diagnóstico de DAC, este deverá ser realizado após interrupção de medicações que interferiram na resposta coronariana (bloqueadores dos canais de cálcio e nitratos) ou na obtenção da FC máxima (betabloqueadores). Não há necessidade de interrupção de outras drogas como IECA, antagonistas dos receptores da angiotensina II ou diuréticos.

Existe controvérsia quanto ao papel do TE na avaliação da resposta pressórica ao esforço. A falta de critérios mais precisos dificulta a sua aplicabilidade. Além disso, nos últimos anos, a MAPA estabeleceu-se como o principal método complementar para o diagnóstico e avaliação terapêutica da HAS. Entretanto, a observação da resposta pressórica ao esforço pode identificar pacientes que necessitam investigação suplementar. Finalmente, programas de condicionamento físico podem ser benéficos para pacientes com HAS e a realização do TE pode permitir uma prescrição mais precisa da carga de trabalho a ser aplicada.
GrauA Investigação de DAC em indivíduos hipertensos com mais de 1 fator de risco (nível 1)

Grau B1 Estudo do comportamento da PA frente ao exercício em indivíduos com história familiar de HAS ou com suspeita de síndrome plurimetabólica (nível 2)

Grau B2 Investigação de HAS em pacientes com evidência de comportamento anômalo (nível 2)

Diagnóstico de DAC em pacientes com HAS e SVEnoECG(nível2)

Diagnóstico de DAC em pacientes com HAS em uso de drogas que alteram a resposta cardiovascular (betabloqueadores, bloqueadores do canal de cálcio e nitratos) (nível 2)

GrauC Avaliação de pacientes com HAS descompensada $(\mathrm{PA}>240 / 120 \mathrm{mmHg})$ (nível3)

\section{I.2.4 - Indicações do TE em valvopatias}

A principal intervenção do cardiologista na história natural das valvopatias, juntamente com o tratamento clínico otimizado, é a definição do momento da indicação cirúrgica. Com o avanço da ecocardiografia, a quantificação não invasiva de lesões não estenóticas e/ou regurgitantes foi simplificada. Porém, a quantificação da classe funcional é fundamental para uma decisão na maioria dos casos. Em paciente com grande limitação funcional, a decisão é simples, mas em pacientes com sintomas atípicos ou que limitam naturalmente sua atividade física, a quantificação objetiva da classe funcional através do TE pode ser de grande utilidade.

As valvopatias também podem ser investigadas quando associadas à suspeita clínica de cardiopatia isquêmica. No entanto, o ECG de repouso de muitos valvulopatas apresentam ARV secundárias à própria valvulopatia, limitando a indicação do TE para diagnóstico de isquemia miocárdica esforço-induzida.

Na estenose aórtica grave ${ }^{20-22}$, sintomática, o TE está contra-indicado. Porém em pacientes com estenose aórtica moderada pouco sintomática, o exame pode ser útil. Nesses, a observação atenta da resposta da PA e a quantificação objetiva da capacidade funcional podem nortear as decisões terapêuticas.

Pacientes com insuficiência aórtica ${ }^{23}$ conseguem manter a capacidade funcional preservada mesmo em fases avançadas da doença. Porém, em pacientes com sintomas questionáveis, a avaliação da resposta de sintomas e/ou FE durante o exercício, através do TE com ou sem ventriculografia radioisotópica ou ecocardiografia de esforço, pode contribuir para identificar IVE mais precoce.

Como a indicação cirúrgica para a estenose mitral ${ }^{23}$ depende fundamentalmente do impacto dessa valvulopatia na capacidade funcional, o TE pode ser de grande utilidade em pacientes com estenose valvar e poucos sintomas. $\mathrm{O}$ aumento anormal da FC, resposta pressórica inadequada e 
indução de dor torácica podem representar comprometimento hemodinâmico grave secundário à obstrução da via de entrada do ventrículo esquerdo.

O comprometimento da capacidade funcional é também um dos principais critérios para indicação cirúrgica na insuficiência mitral. Em pacientes com insuficiência mitral grave ao ECO e com poucos sintomas, a demonstração objetiva da capacidade funcional reduzida e a queda da PA ao exercício podem facilitar a decisão terapêutica.

GrauA Avaliação da capacidade funcional e de sintomas em pacientes com IAo e sintomatologia duvidosa ou de origem não esclarecida (nível 2)

GrauB1 Avaliação da capacidade funcional de pacientes com valvulopatia leve a moderada para esclarecer sintomas, orientar atividade física ou auxiliar na indicação cirúrgica (nível 2)

Avaliação prognóstica antes da troca valvar em pacientes com IAo e IVE (nível 2)

Avaliação em pacientes com IAo para detectar piora na capacidade funcional (nível 2)

Grau B2 Quando associado ao ECO, para avaliação de pacientes com estenose mitral leve (área entre 1.5 e $2.0 \mathrm{~cm}^{2}$ ), sintomáticos (classe funcional IIIV) (nível2)

GrauC Diagnóstico de DAC em pacientes com valvulopatia (nível 2)

Avaliação da capacidade funcional em pacientes com estenose aórtica ou mitral grave (nível 2)

\section{I.2.5 - Indicações do TE na insuficiência car- díaca e cardiomiopatias}

Nas últimas décadas houve grande avanço no conhecimento da fisiopatologia do exercício na ICC com o acúmulo de grande experiência na realização de TE máximos neste cenário. O TE ganha especial utilidade no manejo de portadores de ICC quando realizado simultaneamente com a análise dos gases expirados, na ergoespirometria. $\mathrm{O}$ método permite: diagnóstico de isquemia como fator etiológico na ICC; avaliação objetiva da capacidade funcional ${ }^{24}$; avaliação prognóstica para indicação de transplante cardíaco; avaliação para programas de exercícios e diagnóstico diferencial da dispnéia aos esforços. A classificação da NYHA, obtida facilmente através da anamnese do paciente, permite a avaliação da gravidade da IC, apesar da baixa reprodutibilidade. A classificação objetiva da capacidade funcional, através da medida direta do $\mathrm{VO}_{2}$ máximo na ergoespirometria ${ }^{25,26}$ é fundamental quando implicarem decisões importantes, como a indicação de transplante cardíaco.

Em portadores de qualquer tipo de cardiomiopatia, o TEé utilizado para determinação da vulnerabilidade e avaliação do comportamento de arritmias desencadeadas pelo esforço ${ }^{27}$. Na cardiomiopatia idiopática dilatada, as aplicações são semelhantes àquelas para ICC. No entanto, na cardiomiopatia restritiva e na hipertrófica ${ }^{28}$ com obstrução da via de saída do VE, o TE está contra-indicado. Nas formas não obstrutivas, os protocolos convencionais podem ser aplicados com cuidados especiais para o aparecimento de sinais de obstrução dinâmica, como arritmias ventriculares, queda da PAS e sinais de baixo débito (tonturas, alterações visuais, etc). Na cardiomiopatia chagásica, o TE poderá ser realizado com protocolos convencionais, sendo que a presença de arritmias ventriculares no ECG de repouso não contra-indica o exame.

Existe uma forte correlação entre $\mathrm{o} \mathrm{VO}_{2}$ no pico do exercício e o prognóstico da ICC, valorizado como o marcador prognóstico individual mais importante e utilizado na seleção para transplante cardíaco. Classicamente, o VO tem sido expresso em unidades de volume (L ou $\mathrm{mL})$ em relação à massa corpórea $(\mathrm{kg})$ em função do tempo (min). Pacientes com $\mathrm{VO}_{2}$ de pico $>18 \mathrm{ml} \cdot \mathrm{kg}^{-1} \cdot \mathrm{min}^{-1}$ têm excelente prognóstico e os com $\mathrm{VO}_{2}$ pico $<10 \mathrm{ml} \cdot \mathrm{kg}^{-1} \cdot \mathrm{min}^{-1}$ têm prioridade para transplante. Aqueles como $\mathrm{VO}_{2}$ entre 11 e $18 \mathrm{ml} \cdot \mathrm{kg}^{-1} \cdot \mathrm{min}^{-1}$, entretanto, estão em uma zona onde o $\mathrm{VO}_{2}$, pelo menos na forma como tem sido avaliado, nãoé o melhor índice prognóstico. O problema com essa forma de expressar o $\mathrm{VO}_{2}\left(\mathrm{ml} \cdot \mathrm{kg}^{-1} \cdot \mathrm{min}^{-1}\right)$ é devidoà não permitir correção para diferenças de idade ou sexo, podendo refletir graus diferentes de gravidade nos extremos das faixas etárias. $\mathrm{Um} \mathrm{VO} \mathrm{m}_{2}$ de $15 \mathrm{ml} \cdot \mathrm{kg}^{-1} \cdot \mathrm{min}^{-1}$ pode representarum pior prognóstico em um jovem de 20 anos de idade quando comparado ao mesmo consumo em indivíduo de 50 anos. Apesar das limitações mencionadas, a Sociedade Internacional de Transplante de Coração e Pulmão determina que pacientes com $\mathrm{VO}_{2}$ pico $<14 \mathrm{ml} \cdot \mathrm{kg}^{-1} \cdot \mathrm{min}^{-1}$ sejam aceitos em listas de transplante. A recomendação do Consenso é que o $\mathrm{VO}_{2}$ seja expresso nas duas formas: em referência a um valor previsto por equações, para idade, peso e sexo (\% do previsto) e em relação ao peso $\left(\mathrm{ml} \mathrm{kg}^{-1} \cdot \mathrm{min}^{-1}\right)$.

GrauA Investigação de DAC como causa da ICC em pacientes sem etiologia indefinida (nível 1) Teste com análise de gases para seleção de pacientes para transplante cardíaco (nível 1) Identificação de mecanismos fisiopatológicos e esclarecimento de sintomas (nível 2)

GrauB2 Para elaboração da prescrição de exercício(nível2) Determinação do nível necessário de supervisão e monitorização do programa de exercício (nível 2) Avaliação da gravidade da síndrome (nível 2)

Avaliação da resposta a intervenções terapêuticas (nível 2)

GrauC Miocardite e pericardite aguda (nível 2) Seleção para transplante cardíaco, com base nos valores de $\mathrm{VO}_{2}$ obtidos indiretamente (nível 2) Para diagnóstico de insuficiência cardíaca (nível3)

Apesar de o ideal ser a realização do exame acompanhado da análise dos gases expirados e da ventilação, o TE convencional pode ser empregado com as devidas restrições e adequações. A principal delas diz respeito à não valorização das estimativas de $\mathrm{VO}_{2}$ por fórmulas, as quais podem apresentar grandes variações quando com- 
paradas a medidas diretas. Também deve ser observada a adequação dos protocolos de esforço, com incrementos iguais ou menores que $1 \mathrm{MET}$, idealmente em protocolos de rampa.

A II Diretriz de Insuficiência Cardíaca da SBC, recentemente publicada, contém maiores informações sobre avaliação funcional em ICC.

Aspectos fundamentais da avaliação funcional em ICC - 1) realizar TE apenas em pacientes clinicamente estáveis; 2) individualizar os protocolos (preferir protocolos de rampa); 3) pequenos incrementos de carga ( $\leq 1 \mathrm{MET}) ; 4)$ duração máxima entre 8 e $12 \mathrm{~min}$; 5) preferir testes com medida direta do $\mathrm{VO}_{2}$; 6) utilizar teste de 6 min para avaliação submáxima.

\section{I.2.6 - Indicações do TE na avaliação de taquiarritmias}

Durante o exercício físico ocorre atenuação da atividade parassimpática, aumento da atividade simpática e do consumo de oxigênio miocárdico, respostas fisiológicas que podem favorecer o aparecimento de taquiarritmias. A reprodutibilidade do desencadeamento de arritmias com o exercício é baixa ${ }^{29-31}$. O TE pode identificar pacientes que necessitam maior investigação ${ }^{32,33}$, como nos casos de TV relacionados com displasia arritmogênica do ventrículo direito ou na síndrome do QT longo. Em pacientes com a síndrome de WPW ${ }^{34}$, o TE pode auxiliar quando o objetivo é estratificar risco para aparecimento de TSV com alta resposta ventricular. Finalmente, em pacientes com FA ${ }^{35}$, o TE pode ser útil na avaliação dos efeitos das medicações utilizadas para o controle da resposta ventricular ao exercício.

GrauA Recuperados de PCR, para identificação de DAC ou de arritmias esforço-induzidas (nível 2)

Grau B1 Estabelecimento de correlação entre sintomas e arritmias desencadeados pelo esforço (nível 2)

Estudo da reprodutibilidade e comportamento das arritmias frente ao esforço (nível 2) Avaliação da terapêutica em arritmias desencadeadas ou agravadas pelo esforço (nível 2) Estratificação de risco para desenvolvimento de arritmias na síndrome WPW (nível 2) Detecção de arritmias em portadores de miocardiopatia hipertrófica não obstrutiva (nível 2)

Grau B2 Avaliação de pacientes com arritmias em programas de condicionamento físico (nível 2)

Síndrome do QT longo, com antecedentes ou história familiar de síncope ou morte súbita (nível 2)

GrauC Arritmias paroxísticas em crise (nível 2)

Arritmias ventriculares complexas não-controladas (nível 2)

\section{I.2.7 - Indicações do TE na avaliação de bradiarritmias e marcapasso}

Em pacientes com distúrbios da condução ou do automatismo atrial avançados, que apresentam indicação de MP definitivo, o TE pode ser utilizado para avaliar a resposta do nó sinusal. Tal estratégia visa um melhor planejamento quanto à necessidade de implante de eletrodo atrial, assim como o tipo de estimulação a ser utilizado ${ }^{36}$.

Após o implante do MP, o TE pode ser utilizado para adequar a resposta de freqüência do MP, para avaliar a capacidade funcional e para identificar a presença de arritmias.

Grau A Avaliação da resposta cronotrópica ao exercício em portadores de BAVT congênito (nível 2)

Avaliação da resposta cronotrópica ao exercício em portadores de doença do nó sinusal (nível 2)

Grau B1 Avaliação funcional em pacientes com MP e resposta variável à FC pré-determinada ou dependente de biosensores (nível 2)

GrauC Avaliação de pacientes em uso de MP com freqüência fixa (nível 2)

BAV de grau elevado e baixa frequiência ventricular (nível2)

\section{I.2.8 - Indicações especiais}

Referem-se às aplicações do TE em populações selecionadas para avaliação funcional:

- Cardiopatias congênitas ${ }^{37}$

- Doenças não cardíacas

- Crianças com sopro ou disfunções leves, arritmias ou pós operatório de cardiopatias congênitas

\section{I.3 - Contra-indicações gerais}

São consideradas contra-indicações a presença das se guintes situações ${ }^{38,39}$ :

- Embolia pulmonar

- Enfermidade aguda, febril ou grave

- Limitação física ou psicológica

- Intoxicação medicamentosa

\section{I.4- Contra-indicações relativas}

São situações nas quais devem ser tomadas precauções adicionais para a realização do teste:

- Dor torácica aguda, exceto quando os protocolos disponíveis em unidades de dor torácica sejam seguidos

- Estenoses valvares moderadas

- Insuficiências valvares graves

- Taquiarritmias, bradiarritmias e arritmias ventriculares complexas

- Distúrbios hidro-eletrolíticos e metabólicos

- Afecções não cardíacas capazes de agravamento pelo 
TEe/ou de impedimento para realização do TE (ex: infecções, hipertireoidismo, insuficiência renal, hepática ou respiratória, obstrução arterial periférica, lesões musculares, ósseas ou articulares, deslocamento da retina e afecções psiquiátricas)

\section{I.5 - Condições de alto risco para o TE}

Consideram-se condições de alto risco para o TE aquelas que permitem a realização do TE sob cuidados especiais, obedecidos os parâmetros da relação risco/benefício ${ }^{40-42}$. O TE deve ser realizado somente em ambiente hospitalar, com retaguarda cardiológica adequada, mediante consentimento escrito, após adequado esclarecimento do paciente e/ou de seus responsáveis sobre a indicação do exame.

- IAM não complicado ${ }^{43-45}$

- Angina instável estabilizada ${ }^{46,47}$

- Dor torácica aguda em sala de emergência após seriamento de ECG e enzimas cardíacas ${ }^{48,49,51,55}$

- Lesão conhecida e tratada de tronco de coronária esquerda ou equivalente

- Arritmias ventriculares complexas

- Arritmias com repercussões clínicas e hemodinâmicas sob controle

- Síncopes por provável etiologia arritmogênica BAV avançado

- Presença de desfibrilador implantável

- Insuficiência cardíaca compensada avançada (classe IIINYHA)

- Lesões valvares estenóticas moderadas ou insuficiências graves

- Hipertensão pulmonar

- Cardiomiopatia hipertrófica

- Insuficiência respiratória, renal ou hepática

\section{I.6 - Critérios para realização do TE em sala de emergência}

Os pacientes deverão ser considerados de baixo risco para desenvolvimento de eventos cardiovasculares em 30 dias (risco $<7 \%$ ), pela ausência dos seguintes critérios:

- Hipotensão arterial (PAS $<90 \mathrm{mmHg}$ )

- Presença de terceira bulha

- Estertoração crepitante em bases pulmonares

- Dor torácica considerada como secundária à exacerbação de DAC prévia

- ECG em repouso mostrando alterações de ST sugestivas de isquemia miocárdica em evolução

As seguintes condições são pré-requisitos para realização do TE na sala de emergência:

1) 2 amostras normais de marcadores de necrose miocárdica (CKMB ou troponina) em 8-12 horas de sintomas

2) Ausência de modificações do traçado do ECG de repouso da admissão e imediatamente anterior ao do TE
3) Ausência de alterações do segmento ST que impossibilitem a análise acurada de ECG de esforço

4) Ausência de sintomas no intervalo entre a coleta e resultado da $2^{\mathrm{a}}$ amostra dos marcadores

5) Ausência de dor torácica sugestiva de isquemia no momento do início do TE

São consideradas contra-indicações para a realização do TE na sala de emergência:

- Alterações do segmento ST no ECG de repouso, novas ou em evolução

- Marcadores séricos de necrose miocárdica acima dos valores normais

- Incapacidade para a realização do teste através de esforço

- Piora ou persistência dos sintomas de dor torácica sugestiva de isquemia até a realização do TE

- Perfil clínico indicativo de alta probabilidade para realização de coronariografia

\section{II - Implicações médico-legais do TE}

A despeito do baixo risco inerente à realização do TE e da mínima morbi-mortalidade relatada nos índices epidemiológicos (ocorrência de IAM ou morte $=1 / 10.000 \mathrm{TE}$ ), deve-se conhecer as possíveis implicações jurídicas relacionadas ao procedimento. O tema é abordado nos códigos de Ética Médica, Civil Brasileiro e no de Proteção ao Consumidor, nos artigos abaixo relacionados e mencionados na lei 8.078 de 11/09/1990.

\section{Códigode Ética Médica}

Art.30 É vedado ao médico delegar a outros profissionais atos ou atribuições exclusivos da profissão médica.

Art.31 É vedado ao médico deixar de assumir responsabilidade sobre o procedimento médico que indicou ou participou mesmo quando vários médicos tenham assistido ao paciente.

Art.46 Évedado ao médico efetuar qualquer procedimento médico sem esclarecimento e consentimento prévio do paciente ou de seu responsável legal, salvo em paciente sob eminente risco de vida.

Art.57 É vedado ao médico deixar de utilizar todos os meios disponíveis de diagnóstico e tratamento ao seu alcance em favor do paciente.

Art. 69 É vedado ao médico deixar de elaborar prontuário médico para cada paciente.

Art. 3 A fim de que possa exercer a medicina com honra e dignidade, o médico deve ter boas condições de trabalho e ser remunerado de forma justa.

\section{Código Civil Brasileiro}

Art.159 Aquele que, por ação ou omissão voluntária, negligência ou imprudência, violar direito, ou causar prejuízo a outrem, fica obrigado a reparar o dano.

\section{Código de Proteção ao Consumidor}

Art. 6.1 São considerados direitos básicos do consumidor: a proteção da vida, saúde e segurança contra os 
riscos provocados por práticas no fornecimento de produtos e serviços considerados nocivos ou perigosos.

Art. 6.3 É obrigação do fornecedor informar adequada e claramente sobre os produtos e serviços prestados, com especificação correta de quantidade, características, composição, qualidade e preço, bem como os riscos que apresentam.

Art. 14 O fornecedor de serviços responde, independente da existência de culpa, pele reparação dos danos causados ao consumidor, por defeitos relativos à prestação de serviços, bem como por informações insuficientes ou inadequadas sobre sua função e riscos.

Considerando as informações acima expostas como verdadeiras, sob o ponto de vista legal e, portanto, passíveis de serem aplicadas a um serviço prestado, há necessidade de se definir as responsabilidades médicas básicas. Estas podem ser traduzidas, como nos dizeres de Duarte e Alfieri, de duas maneiras: 1) o paciente deve ser conscientizado dos riscos previsíveis do procedimento, além de consentir a sua realização; 2) o procedimento deve ser realizado cuidadosamente e todas as providências tomadas para minimizar os possíveis riscos.

1) A realização do TE deve ser precedida da solicitação médica escrita.

2) TE deve ser realizado em todas as sua etapas por médico habilitado.

3) Deve incluir história clínica, exame físico, ECG convencional basal e a realização do TE conforme solicitado.

4) No pós esforço, registros eletrocardiográficos deverão ser realizados.

5) Paciente será liberado da sala de exame após seu restabelecimento às condições basais adequadas.

6) A emissão de laudo deverá ser precedida de interpretação clínica e eletrocardiográfica, além de orientação do paciente para retorno ao médico assistente.

7) A remuneração do profissional deve contemplar honorários médicos e custo operacional

8) Recomenda-se a utilização do consentimento informado assinado pelo paciente e por duas testemunhas.

9) Na eventualidade de acidentes de natureza grave ou fatal decorrentes do procedimento, sugere-se a comunicação e solicitação de parecer da comissão de ética do Conselho Regional de Medicina.

\section{III - Metodologia}

A aplicação do TE objetivando avaliar respostas clínicas, eletrocardiográficas e hemodinâmicas, necessita, obrigatoriamente, de rigorosa obediência às condições básicas da metodologia do procedimento. Somente assim podem ser obtidos resultados fiéis, reprodutíveis e mensuráveis.

\section{III.1 - Condições básicas para a programação do teste}

As referidas condições básicas contempla aspectos relacionados a: equipe médica, área física, equipamentos da sala de ergometria, material e medicamentos para emergência e orientações ao paciente.

Equipe médica - O médico com experiência no método é o responsável pela condução da prova, podendo ser auxiliado por pessoal técnico, especificamente treinado, na execução do TE e em eventual atendimento de emergência.

Área física - Deve ter luminosidade, ventilação e dimensões suficientes para acomodação da aparelhagem necessária e permitir circulação de pelo menos três pessoas, com temperatura ambiente entre 18 e $22^{\circ} \mathrm{C}$.

Equipamentos - 1) cicloergômetro de frenagem mecânica ou eletromagnética e/ou esteira rolante, com velocidade e inclinação variáveis. Ergômetro de manivela como alternativo; 2) monitor para observação contínua e eletrocardiógrafo para registro do ECG e análise do comportamento da freqüência cardíaca 3) esfigmomanômetro calibrado e estetoscópio; 4) cronômetro.

Material e medicações para emergências - Deverão estar disponíveis para o adequado tratamento de emergências todo o material incluído no suporte básico e avançado de vida. A equipe de apoio devem ter treinamento em suporte básico de vida.

Orientações ao cliente fica às recomendações do médico assistente ao cliente - a) motivo do teste de esforço; b) decidir sobre a suspensão ou manutenção da medicação vigente. Na primeira condição, delegar ao laboratório o tempo necessário para suspensão das medicações.

\section{III.2 - Registros eletrocardiográficos}

Os registros devem obedecer uma seqüência lógica com a obtenção dos seguintes traçados: repouso, durante cada estágio de exercício ou a critério médico; recuperação; na presença de arritmias documentando e relatando sua provável origem, complexidade, freqüência e momentode aparecimento.

Tabela I - Tempo de suspensão dos medicamentos para realização do TE, Quando a finalidade é diagnóstica.

\begin{tabular}{|lc|}
\hline Medicação & Dias de suspensão prévia \\
\hline AAS & 1 \\
Amiodarona & 30 \\
Betabloqueadores & De 4 a 8 \\
Bloqueadores dos canais de cálcio & De 1 a 4 \\
Dipiridamol & 1 \\
Digoxina & De 7 a 10 \\
Inibidores da ECA & 1 \\
Diuréticos & 3 \\
Anti-arrítmicos & De 3 a 5 \\
Nitrato & 1 \\
Metildopa e clonidina & 1 \\
\hline Obs: considerando-se que o fenômeno de rebote pode ser evidenciado na \\
suspensão dos betabloqueadores e de alguns agentes anti-hipertensivos, \\
salienta-se a necessidade de retirada gradual do fármacos antes do exame. \\
\hline
\end{tabular}




\section{III.2.1 - Sinais e sintomas}

Observação e anotação dos sinais e sintomas, tais como palidez, tonturas, sudorese, estafa física e dispnéia, relacionando-os à condição hemodinâmica e à resposta eletrocardiográfica frente ao esforço. Há necessidade de caracterização pormenorizada do sintoma dor torácica, avaliando seu processo de aparecimento, momento, intensidade, evolução, caráter, fenômenos associados e irradiação. A ausculta cardíaca e pulmonar além da obrigatória no exame clínico inicial, devem ser obrigatoriamente repetidas no pós-esforço imediato.

\section{III.2.2 - Sensação subjetiva de cansaço}

A percepção subjetiva da intensidade do esforço pelo cliente pode ser expressa através de valores numéricos, contribuindo significativamente para a interpretação dos resultados. Mais comumente se emprega uma das duas escalas de Borg, que variam entre zero e 10 ou de 6 a 20, representando respectivamente, sensação de esforço do muito fácil ao esforço exaustivo. Ambas escalas correlacionam-se com o percentual da FC máxima atingida durante o exercício. O questionamento ao paciente sobre a sensação de esforço a cada minuto ou estágio do exercício deve ser considerado.

\section{III.3 - Critérios de interrupção do esforço}

Elevação da PAD até $120 \mathrm{mmHg}$ nos normotensos; elevação da PAD até 140mmHg nos hipertensos; queda sustentada da PAS; elevação acentuada da PAS até $260 \mathrm{mmHg}$; manifestação clínica de desconforto torácico, exacerbada com o aumento da carga ou que associada a alterações eletrocardiográficas de isquemia, ataxia, tontura, palidez e pré-síncope; dispnéia desproporcional à intensidade do esforço; infradesnível do segmento ST de $0,3 \mathrm{mV}$ ou $3 \mathrm{~mm}$, adicional aos valores de repouso na presença de DAC suspeita ou conhecida; supradesnível do segmento ST de $0,2 \mathrm{mV}$ ou $2 \mathrm{~mm}^{48,49}$, em derivação que observe região sem presença de onda Q; arritmia ventricular complexa; aparecimento de TSV sustentada, taquicardia atrial, FA, BAV de $2^{\circ}$ ou $3^{\circ}$ graus; IVE, com atenção especial no indivíduo idoso, uma vez que o achado de estertores crepitantes à ausculta pulmonar não é infreqüente, mesmo na ausência de sintomas; falência dos sistemas de monitorização e/ou registro.

\section{III.3 - Escolha do protocolo}

O protocolo a ser executado em um determinado teste deve sempre levar em consideração as condições específicas do paciente. Para tanto, deve-se proceder a uma escolha individualizada, de tal forma que a velocidade e a inclinação da esteira ou a carga da bicicleta possam ser aplicadas em acordo com a capacidade do paciente testado. Para isto, podem ser utilizados diferentes protocolos: a) Rampa - são protocolos que utilizam pequenos incrementos na carga a cada estágio, permitindo uma mensuração mais acurada da capacidade funcional, especialmente quando aplicados individualmente, baseados em questionários da atividade física da vida diária do paciente (escala de atividade de $D u$ ke ou o questionário do VACM). Além disso, tais protocolos permitem que o médico possa ajustar o mesmo a uma duração ótima do teste, a qual deve variar idealmente entre 8 a $12 \mathrm{~min}$.

b) Protocolos mais intensos podem ser utilizados em indivíduos fisicamente ativos e/ou em jovens aparentemente saudáveis, sendo os protocolos de Bruce ou de Ellestad os mais aplicados.

c) Quando a população em teste apresenta limitações etárias e/ou funcionais, protocolos com incrementos menos intensos devem ser priorizados. Nestas situações os protocolos de Naughton ou de Balke servem como exemplos.

\section{III.3.1 - Protocolos para cicloergômetro}

Uma sugestão de protocolo a ser utilizado com o cicloergômetro é o protocolo de Balke com incremento de cargas de $25 \mathrm{w}$ a cada $2 \mathrm{~min}$. Em indivíduos jovens e sadios recomenda-se iniciarcom $50 \mathrm{w}$, jáem indivíduos limitados deve-se iniciarcom carga livre e nos demais pacientes deve-se começar com 25 w. A estimativa da $\mathrm{VO}_{2}$ máxima para cicloergômetroé assim calculada: $\mathrm{VO}_{2}$ máxima $=(12 \mathrm{x}$ carga em watts $)+300 /$ pesoem $\mathrm{kg}$.

\section{III.3.2 - Protocolos para esteira rolante}

Uma sugestão de protocolo a ser utilizado com a esteira rolante é o protocolo de Bruce (o mais utilizado em nosso meio), que apresenta aumentos progressivos da velocidade e da inclinação. Como o incremento de trabalho é grande (não linear), deve ser usado com prudência em indivíduos clinicamente limitados. Está preferencialmente indicado para estabelecimento de diagnóstico e/ou avaliação da capacidade funcional, em indivíduos que possuam algum grau de condicionamento físico. A estimativa do $\mathrm{VO}_{2}$ máximo para esteira rolante é assim calculada: homens - (2.9 x tempo em minutos) $+8,33$; mulheres $-\mathrm{VO}_{2}=(2,74 \mathrm{x}$ tempo em minutos $)+8,03$.

Outra sugestão para ser utilizada em esteira é o protocolo de Ellestad que possui aplicação semelhante ao de Bruce, mas com menor utilização na prática. Esse protocolo também emprega aumentos expressivos de carga a partir do estágio 3. O protocolo de Naughton é reservado para indivíduos com limitações físicas importantes, em especial idosos e sedentários, bem como em paciente em evolução recente de IAM e em portadores de ICC compensada.

Os protocolos para ergômetros de manivelas são indicados em situações especiais (exemplo: atletas que trabalhem predominantemente com os membros superiores ou indivíduos que apresentem limitações físicas nos membros inferiores). Nesses ergômetros a aplicação do esforço se faz através dos braços. Quando não existem ergômetros espe- 
cíficos, pode-se inverter o de pernas e fazer o exercício com o braços. São utilizados os mesmos protocolos de cicloergômetros para realização dos exercícios com as pernas, sendo que os incrementos de cargas são reduzidos à metade.

Recentemente, tem havido um maior interesse por protocolos de rampa. Esse interesse encontra subsidio no fato da rampa poder atender às características de linearidade nas respostas do consumo de oxigênio. Estes protocolos ao invés de estágios de duração definida, utilizam uma razão de incremento constante para a intensidade do esforço, que permite uma maior individualização e adaptação do protocolo às condições do paciente. Os protocolos de rampa podem ser realizados tanto em esteiras rolantes quanto em cicloergômetros.

\section{IV - Respostas clínicas e eletrocardiográficas frente ao esforço}

\section{IV.1 - Respostas hemodinâmicas IV.1.1 - Freqüência cardíaca}

Aumenta linearmente com a intensidade do esforço e, consequentemente, com o consumo de oxigênio, dentro de limites definidos (faixa de 50 a $90 \%$ do $\mathrm{VO}_{2}$ máximo). O parâmetro teórico denominado FC máxima varia, inversamente, com a idade e pode ser previsto por equações simples, já mencionadas. Sua elevação desproporcional em relação à carga de trabalho imposta é usualmente encontrada em sedentários, em indivíduos muito ansiosos, na distonia neurovegetativa, hipertireoidismo e em estados anêmicos. A incompetência cronotrópica ${ }^{50,51}$ ou dificuldade de ascenso da FC frente ao nível de esforço empregado pode ser sinal de coronariopatia ou miocardiopatia, e definidas como a incapacidade do paciente elevar a FC a um valor inferior a 2 desvios padrão da FC máxima prevista (24bpm), sem outras limitações concomitantes. A queda da FC com a progressão do esforço, apesar de ser um achado raro, apresenta alta correlação com doença isquêmica, sendo critério absoluto para interrupção do esforço. O retardo na redução da FC no 1 - minuto pós-teste, que pode ser devido a diminuição da atividade vagal, tem sido associado a uma maior mortalidade total ${ }^{52,53}$. Esse achado é definido como uma redução de

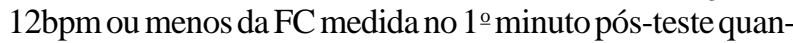
do comparada a FC do pico máximo de exercício.

Ocasionalmente, indivíduos jovens e sadios, exercitados até a exaustão, podem desenvolver no pós-esforço imediato, episódios de bradicardia sinusal e, eventualmente, progredir a pausas maiores até segundos de assistolia, resultado de reação vagal reflexa (síncope vaso-vagal). $\mathrm{Na}$ prática clínica, entretanto, a maior causa de interferência na resposta cronotrópica é atribuída à utilização de fármacos específicos na época da realização do exame (betabloqueadores, bloqueadores do canal de cálcio, digitálicos, etc).

\section{IV.1.2 - Pressão arterial}

Principal elemento para avaliação indireta da resposta inotrópica do coração em relação ao esforço, conjuntamente ao grau de tolerância ao exercício. Em condições normais, durante o TE, a PAS aumenta com a intensidade crescente do trabalho aplicado (em geral até $220 \mathrm{mmHg}$ ) e PAD mantém-se constante ou oscila cerca de $10 \mathrm{mmHg}$. Ainda não existe consenso sobre os valores normais de variação da PA com esforço. Sugere-se que diferenças devam ser definidas para indivíduos jovens e idosos, mulheres e homens, brancos e negros, necessitando-se de estudos adicionais para o estabelecimento de padrões. A despeito destas dificuldades, conceitua-se hipertensão reativa ao esforço como o achado de valores de PAS >220mmHg e/ou elevação de $15 \mathrm{mmHg}$ ou mais de PAD, partindo de valores normais de pressão em repouso. Sugere-se que indivíduos que apresentam resposta hiperreativa frente ao esforço têm probabilidade futura 4 a 5 vezes maior de se tornarem hipertensos, em relação aqueles com curvas normais de pressão arterial. Por outro lado, a elevação inadequada da PAS ${ }^{54}$ é sugerida quando seu gradiente intra-esforço (delta PS) é $<35 \mathrm{mmHg}$, na ausência de acentuada queda na PAD, podendo, em indivíduos com suspeita ou diagnóstico de cardiopatia isquêmica, representar disfunção contrátil do miocárdio. Maior valor preditivo para doença isquêmica grave tem queda do componente sistólico da PA durante o esforço. Também não encontram consenso os critérios de hipotensão frente ao esforço, sendo o achado de níveis de PAS no exercício inferiores ao de repouso, índice de pior prognóstico. Leve hipotensão sistólica no esforço máximo pode ocorrer em indivíduos jovens, bem condicionados. A elevação da PAS nos três primeiros minutos pós-teste, acima dos valores máximos atingidos durante a fase de esforço, tem sido correlacionada à DAC. Também a recuperação lenta da PAS pósesforço tem sido associada a DAC angiograficamente demonstrada. Esta recuperação lenta é caracterizada quando a razão entre o valor da PAS no 3ำ minuto pós-esforço pelo valor do pico do esforço é maior que 0,95 , ou ainda, quando a razão entre a PAS no $3^{\circ}$ - minuto pela razão do $1^{\circ}$ minuto pós-esforço é > 1,0. Igualmente, hipotensão arterial no período pós-esforço em indivíduos aparentemente sadios, a despeito de aumentar a incidência de arritmias, não tem associação com morbi-mortalidade cardiovascular, sendo mais freqüente em indivíduos jovens exercitados até a exaustão. As mulheres representam capítulo a parte na ergometria, apresentando variações da PA sistêmica no esforço sensivelmente menores que os homens. Níveis fixos (comportamento em platô) e, eventualmente queda da PAS, podem ser registrados em mulheres sem outras evidências de cardiopatias, inclusive em casos com boa tolerância ao esforço.

\section{IV.2 - Respostas eletrocardiográficas}

Onda $\boldsymbol{P}$ - Aumento da fase negativa nas derivações V1 e/ou V2 poderia indicar disfunção ventricular esquerda.

Segmento PR - Tem sua duração diminuída, tornandose infradesnivelado por influência da onda $\mathrm{T}$ de repolarização atrial;

Onda $\boldsymbol{Q}$ - A diminuição da amplitude ou desaparecimento durante ou após o esforço podem indicar isquemia 
septal, em populações selecionadas. O aparecimento de vetores septais contralaterais de isquemia, somados aos vetores opostos de despolarização septal normal, resultariam em diminuição ou desaparecimento do vetor resultante final. De pequeno valor quando a deflexão é analisada isoladamente, não deve ser avaliada em portadores de BRE/BRD, região acometida de IAM ou na síndrome de pré-excitação. Da mesma forma, a diminuição ou desaparecimento de Q associa-se a desnivelamentos verdadeiros positivos de ST, enquanto seu aumento associa-se a falso-positivos.

Onda $\boldsymbol{R}$ - Tem sua amplitude afetada por um grande número de fatores, e atualmente, em seu comportamento frente ao exercício, é considerada sem valor diagnóstico.

Onda $\boldsymbol{S}$ - Não apresenta valor específico para diagnóstico de isquemia durante o exercício.

Segmento ST - Os deslocamentos negativos e positivos, vislumbrados pelo observador em relação à linha de base do ECG, são as manifestações mais freqüentes relacionadas à isquemia miocárdica.

Supradesnivelamento do $\boldsymbol{S T}$ - Achado infreqüente durante a realização do $\mathrm{TE}^{48,49}$, tem sua prevalência na dependência da população estudada. É de ocorrência comum em pacientes com IAM com Q e, à semelhança da depressão do segmento ST. É quantificado como resposta anormal o desvio positivo de $1 \mathrm{~mm}$ (medido ao nível da junção J/ST) em relação à linha de base imaginária que une a junção PQ de pelo menos 2 complexos QRS sucessivos. Quando ocorre em derivações com onda $Q$ devido a IAM prévio, o significado do supradesnivelamento do segmento ST é controverso. Alguns estudos têm sugerido que seja devido às anormalidades da contratilidade ventricular (discinesia, acinesia ou presença de zona aneurismática). Outros estudos, no entanto, têm evidenciado ser um marcador de viabilidade miocárdica residual. Em derivações sem a presença de onda Q, salvo em aVR e V1, associa-se a lesões de tronco de coronária esquerda ou proximais (freqüiente comprometimento da artéria descendente anterior), ou ainda, a espasmo coronariano. Elevação de ST em ECG normal (outra além de aVR ou V1) representa isquemia transmural, sendo achado pouco prevalente nos laboratórios de ergometria $(<0,1 \%$ dos exames). Quando a elevação de ST ocorre de V2 a V4 existe correlação com o envolvimento de artéria coronariana descendente anterior. Quando sua ocorrência se dá em derivações laterais, a artéria circunflexa costuma estar envolvida e quando em DII, DIII e aVF, a artéria coronária direita está envolvida.

Infradesnivelamento do ST no pós-esforço - Esse achado é atualmente valorizado de maneira semelhante à sua ocorrência durante a fase de esforço.

Pseudonormalização ou ausência de mudanças na onda T e/ou no ST - Anormalidades eletrocardiográficas em repouso (inversão da onda T e/ou depressão do ST), podem retornar ao normal durante episódios anginosos e no exercício em alguns pacientes com DAC obstrutiva. Essa modificação infreqüente tem sido descrita como uma pseudonormalização do segmento ST que ocorre devido ao "efeito de cancelamento", situação na qual a normalização do infradesnível prévio do ST é na verdade uma elevação do segmento ST associada à isquemia transmural ${ }^{55}$. Um determinado paciente poderá ter o seu "melhor" traçado durante um típico episódio de isquemia. No entanto, é importante saber que esse padrão de normalização do segmento ST (pseudonormalização verdadeira), somente terá significado isquêmico se houver a presença concomitante de dor anginosa ou de algum equivalente anginoso durante o TE.

Onda $\boldsymbol{T}$ - A positivação de uma onda T previamente negativa ou a negativação de uma positiva no repouso, em indivíduos sem outros achados significativos no TE são considerados achados inespecíficos e sem valor diagnóstico para isquemia. Em derivações com zona inativa de IAM prévio, a positivação de uma onda T previamente negativa (pseudonormalização de T), tem sido associadas a áreas de viabilidade miocárdica.

Bloqueio do ramo esquerdo - Geralmente, indica anormalidade, sendo que seu valor preditivo para DAC depende da prevalência da doença na população testada. Algumas condições estão freqüentemente associadas como degeneração do sistema de condução, miocardites, cardiomiopatias e HVE. Eventualmente, pode ocorrer em pessoas normais. Fica invalidada a análise das alterações de ST/T em relação a isquemia.

Arritmias ventriculares - De elevada incidência durante e após o exercício, têm sua prevalência diretamente relacionada à idade. Trabalhos relatam a ocorrência em até $50 \%$ dos exames de indivíduos considerados normais no aspecto cardiovascular. As ESV isoladas são os fenômenos predominantes, com comportamentos variados. Podem ser induzidas ou suprimidas pelo exercício, estar presentes desde o repouso ou somente na recuperação, tanto em indivíduos normais quanto em pacientes com DAC. As induzidas pelo exercício são consideradas anormais quando ocorrem em número superior a 10 ESV monomórficas por minuto, manifestando-se durante o exercício ou na recuperação. Além disso, podem apresentar maior complexidade (polimorfismo, pareadas, em salvas, TV). Quando presentes em repouso, o aumento da FC ou complexidade de ESV nas fases subsequentes deve ser valorizado. A especificidade para o diagnóstico de isquemia é baixa, elevando-se quando a arritmia é induzida em carga baixa e associada a alterações do ST ou outros de maior valor preditivo. O achado de ESV em 2 batimentos consecutivos ou mais, ou ainda isoladas, porém representando mais do que $10 \%$ dos complexos durante 30 s de qualquer registro do teste, tem sido associado, em homens assintomáticos, a um maior risco de mortalidade cardiovascular.

\section{TE em associação com outros métodos}

Os métodos complementares não invasivos associados ao TE que fazem parte da metodologia de avaliação dos cardiopatas, são a cintilografia de perfusão miocárdica, a ventriculografia radioisotópica, a ecocardiografia com estresse farmacológico ou com o exercício e o teste cardiopulmonar integrado (ergoespirometria). Sua utiliza- 
ção permite superar as limitações do TE, quer por problemas inerentes ao método, quer por características peculiares da população estudada.

Grau B1 Testes anormais em portadores de doença cardíaca valvar; doença cardíaca congênita; cardiomiopatias; hipertrofia ventricular esquerda (inclusive a do atleta); duplo produto elevado Situações onde não é possível utilizar os critérios eletrocardiográficos: BRE; síndrome de WP W; variantes da síndrome de pré-excitação; supradesnível do segmento ST em área eletricamente inativa; utilização de fármacos específicos (compostos digitálicos, hormônios femininos).

Situações onde é preciso definir anatomicamente a zona isquêmica: na presença de sintomas sugestivos de DAC, em pacientes submetidos a revascularização do miocárdio incompleta, cirúrgica ou por ATC

Situações onde o TE foi ineficaz: testes normais nos pacientes com incompetência cronotrópica e/ou capacidade funcional $<5 \mathrm{METS}$ e/ou déficitinotrópico e/ou arritmias complexas induzidas ao esforço.

Grau B2 Situações onde há discordância entre a probabilidade pré-teste e o resultado: em indivíduos com alta probabilidade de DAC pré-teste e TE normal ou baixa probabilidade pré-teste de DAC e TE anormal

\section{V.1 - Cintilografia de perfusão do miocárdio}

A realização complementar da cintilografia miocárdica está indicada na avaliação pré e pós procedimentos de CRM; complementação de TE não conclusivo ${ }^{56}$, detecção da severidade e extensão da área isquêmica ${ }^{57}$ e em situações em que fica prejudicada a identificação dos sinais de isquemia, como as zonas extensas de necrose ${ }^{58}$. A detecção de isquemia miocárdica em pacientes que estão em uso de fármacos que interferem nos padrões do ECG; a constatação da ausência de isquemia em testes falso-positivos e a presença de isquemia em testes falso-negativos são também algumas das indicações da cardiologia nuclear.

GrauA Complementação de TE não conclusivos (nível 2). Situações em que fica prejudicada a identificação dos sinais de isquemia. (nível 2).

Identificação de isquemia na vigência de fármacos que interferem noECG(nível2).

Constatação da ausência de isquemia em testes falso-positivos e da presença de hipocaptação dependente de DAC frente a testes falso negativos (nível 2).

Grau B1 Correlação anátomo-funcional pós-cineangiocoronariografia (nível 2).

Grau B2 Após IAM, para verificar a extensão, a viabilidade e o comprometimento de outras artérias (nível 2).
GrauC Controle evolutivo dos pacientes com testes anormais em programa de exercícios (nível 2). $1^{\mathrm{a}}$ escolha na estratificação de risco para DAC, em pacientes sem contra-indicação para TE (nível2).

Os radiofármacos disponíveis utilizados são o tálio 201 e a 2-metil-isobutil-isonitrila (MIBI), ambos com capacidades similares em relação aos defeitos de perfusão miocárdica na DAC. Na pesquisa de viabilidade miocárdica há preferência pelo tálio201 em relação ao MIBI.

Os tipos de estresse a que se pode submeter o paciente para realização da cintilografia de perfusão miocárdica são o estresse físico em cicloergômetro ou esteira rolante, sendo este o mais utilizado, e o estresse farmacológico com dipiridamol, adenosina ou dobutamina ${ }^{59}$, na vigência de impossibilidade ou limitação para realizar o exercício físico. As indicações para a realização do estresse farmacológico são doença vascular periférica ou cerebral; IC; distúrbios músculo-esqueléticos e neurológicos; DPOC; baixa capacidade funcional; HAS moderada a grave; vigência de medicamentos que limitam a resposta funcional ao esforço (betabloqueadores, bloqueadores do canal de cálcio).

Os agentes atualmente utilizados para as provas farmacológicas são dipiridamol (maior experiência acumulada), adenosina e dobutamina. Estudos têm demonstrado que as provas de esforço e o estímulo farmacológico com dipiridamol são comparáveis, em relação às imagens obtidas. Em algumas condições, no entanto, como no BRE, o estresse farmacológico com dipiridamol parece ser superior aos demais fármacos. As contra-indicações para o uso de dipiridamol ou adenosina são: asma brônquica, DPOC dependente de derivados das xantinas, hipotensão arterial sistólica $(<90 \mathrm{~m}$ $\mathrm{mHg})$, bradicardia significativa, $\mathrm{BAV}\left(2^{\circ} / 3^{\circ}\right)$ não protegidos por MP artificial, angina instável; e para o uso de dobutamina: angina instável, fase aguda do IAM, cardiomiopatia hipertrófica obstrutiva, arritmias complexas, HAS não controlada, dissecção de aorta, aneurismas arteriais.

\section{V.3 - Ecocardiografia de estresse}

Método eficiente para a avaliação da função sistólica global e segmentar do VE, na pesquisa de isquemia miocárdica ${ }^{60}$ e para a avaliação funcional de cardiomiopatias e valvopatias. É considerado equivalente àquele disponibilizado pela cardiologia nuclear, com sensibilidade e especificidade similares. Pode ser associada tanto ao esforço físico quanto à utilização de drogas, seguindo os mesmos critérios já descritos para a cintilografia.

Atualmente, alguns centros estão utilizando contrastes, o que permite a avaliação conjunta da perfusão miocárdica e da contratilidade. Ainda não existe consenso sobre a utilização de contraste na ecocardiografia.

GrauA Avaliação de viabilidade miocárdica (nível 2). Avaliação de áreas de risco no pós-IAM (nível2). ECG basal com alterações significativas (HVE, BRE) (nível 2). 
TE de indivíduo assintomático com marcadas alterações no ECG de esforço (nível 2).

Grau B1 Avaliação de valvopatias (nível 2).

Avaliação de miocardiopatias (nível 2).

TE de indivíduos sintomáticos e com ECG de esforço normal (nível 2).

Grau B2 Avaliação pré-operatória de grandes cirurgias em pacientes idosos e/ou incapazes de realizar exercício (uso do eco de estresse com drogas) (nível2).

\section{V.4 - Ergoespirometria (teste cardiopulmonar de exercício)}

O TE convencional se baseia na análise das respostas clínicas, eletrocardiográficas e hemodinâmicas, sem incluir variáveis ventilatórias. Quando o objetivo é identificar o(s) motivo(s) para a interrupção do esforço ou quantificar esta limitação ${ }^{61}$, o TE convencional não é o melhor método a ser utilizado, pois não é capaz de fornecer informações acuradas e esclarecedoras.

O teste cardiopulmonar de exercício acrescenta à ergometria convencional a quantificação da ventilação pulmonar e das frações expiradas de oxigênio e gás carbônico durante o esforço. Um oxímetro de pulso deve ser utilizado para quantificar a saturação de hemoglobina. Em laboratórios mais sofisticados, podem ser realizados outros procedimentos, como reinalação de gases, ou ainda, testes invasivos, com a colocação de cateteres intra-arteriais e de Swan-Ganz.

GrauA Seleção de pacientes para transplante cardíaco (nível2).

Identificação de mecanismos fisiopatológicos no diagnóstico diferencial de dispnéia (nível 2).

Avaliação da gravidade da síndrome de IC (nível 2). Prescrição de exercício em atletas de ponta, pacientes com ICC, pneumopatias ou obesos (nível 2). Estimativa de prognóstico em pacientes portadores de IVE sintomáticos (nível 2).

Grau B1 Avaliação de resposta a intervenções terapêuticas (nível2).

Quantificação precisa da potência aeróbia em indivíduos em programas de exercício físico (nível 2).

Grau B2 Avaliação da resposta a programas de reabilitação (nível 2).

Limiar anaeróbio - Uma das vantagens da ergoespirometria é a identificação não invasiva do limiar anaeróbio e do ponto de compensação respiratória através da análise de curvas ventilatórias. Há na literatura, uma falta de homogeneidade de conceitos desses pontos metabólicos, gerando dificuldades na elaboração de trabalhos científicos e laudos para prescrição de exercício. Para efeito de padronização, utilizaremos os conceitos de Wasserman:

$1^{\circ}$ limiar ventilatório ou anaeróbio é caracterizado pela perda da linearidade entre a $\mathrm{VE}$ e $\mathrm{VO}_{2}\left(\mathrm{VE} / \mathrm{VO}_{2}\right.$ mais baixo antes de aumento progressivo), aumento da razão de trocas respiratórias $(\mathrm{R})$ ou aumento progressivo de $\mathrm{PET}_{2}$ ou FE $\mathrm{CO}_{2}\left(\mathrm{PETO}_{2}\right.$ ou FECO ${ }_{2}$ mais baixo). Olimiar anaeróbio também é obtido com equações de regressão pelo método computadorizado do V-slope, devendo ser comparado ao obtido através da análise visual.

$2^{\circ}$ limiar ventilatório ou ponto de compensação respiratória para acidose metabólica é caracterizado pela perda da linearidade da relação entre $\mathrm{VEe} \mathrm{VCO}_{2}\left(\mathrm{VE} / \mathrm{VCO}_{2}\right.$ mais baixo, antes de aumento progressivo, queda de $\mathrm{PET} \mathrm{CO}_{2} \mathrm{Ou}$ $\mathrm{FECO}_{2}\left(\mathrm{PETCO}_{2}\right.$ ou $\mathrm{FECO}_{2}$ mais alto, precedendo sua queda abrupta).

Considerando as diferentes metodologias, é recomendado descrever no laudo o critério utilizado para identificação do limiar anaeróbio.

Consumo máximo de oxigênio - A mais importante variável de avaliação da condição aeróbia pelo teste cardiopulmonaré o $\mathrm{VO}_{2}$ máx. A identificação do $\mathrm{VO}_{2}$ máx em um teste com aumento progressivo de carga ocorre quando o aumento no trabalho não ocasiona elevação do $\mathrm{VO}_{2}(\mathrm{au}-$ mento inferior a $50 \mathrm{~mL} \cdot \mathrm{min}^{-1}$, ou 2,1 mL. $\mathrm{kg}^{-1} \cdot \mathrm{min}^{-1}$ ). Quando este critério não é obtido, o termo $\mathrm{VO}_{2}$ pico é utilizado para identificar o maior $\mathrm{VO}_{2}$ atingido. Para a maioria das situações clínicas estaremos nos referindo a um $\mathrm{VO}_{2}$ pico. Classicamente, $\mathrm{O} \mathrm{VO}_{2}$ tem sido expresso em unidades de volume ( $\mathrm{L}$ ou $\mathrm{mL})$ em relação à massa corpórea $(\mathrm{kg})$ em função do tempo (min). O problema com essa forma de expressar o $\mathrm{VO}_{2}\left(\mathrm{ml} \cdot \mathrm{kg}^{-1} \cdot \mathrm{min}^{-1}\right)$ é o fato de não permitir correção para diferenças de idade ou sexo, podendo refletir graus diferentes de gravidade nos extremos das faixas etárias. A recomendação do Consenso é que o $\mathrm{VO}_{2}$ seja expresso nas duas formas: em referência a um valor previsto por equações, para idade, peso e sexo (\% do previsto) e em relação ao peso $\left(\mathrm{ml}^{\mathrm{kg}} \mathrm{kg}^{-1} \cdot \mathrm{min}^{-1}\right)$.

\section{VI - Elaboração do laudo do TE}

Uma vez concluído o procedimento e após a análise e interpretação dos resultados, deve-se preparar um laudo para o médico solicitante. Deve-se considerar que o teste é um procedimento que colabora, mas não substitui a decisão clínica. Por este motivo, deve ser explicitado no laudo como os resultados desse teste deverão ser interpretados, com os dados clínicos do paciente, pelo seu médico assistente, a quem cabe julgar, decidir e orientar a conduta clínica necessária.

Muito embora existam diferentes formas de apresentação desse laudo, algumas informações são imprescindíveis e deverão constar em todos os relatórios conclusivos. Essas informações podem ser classificadas em algumas categorias a saber: 1) descrição geral; 2) resultados; 3) interpretação e 4) conclusões.

\section{VI.1 - Descrição geral}

Identificação do paciente e do exame, incluindo nome, sexo, idade, dados antropométricos, data e horário de realização; 
Características clínicas do paciente, incluindo indicação, principais dados da anamnese e exame físico pertinentes e medicação em uso (preferencialmente com hora da última tomada).

Condições de realização do exame, incluindo temperatura e umidade da sala, ergômetro e protocolo utilizados.

\section{VI.2 - Resultados}

Motivo(s) para interrupção do teste e presença de sinais e sintomas anormais associados ao procedimento. Deve-se destacar quando for interrompido precocemente pelo médico;

Principais dados obtidos no repouso, nos diferentes estágios ou minutos do teste e nos minutos iniciais da recuperação, com destaque para a FC, PAS e PAD, intensidade do esforço e sinais e sintomas, preferencialmente em forma tabular e, também, de forma gráfica. A capacidade funcional e a potência aeróbica máxima devem ser quantificadas, seja de forma direta (em termos absolutos e relativos ao peso corporal) ou indireta.

Principais achados eletrocardiográficos, com ênfase no segmento ST e em arritmias supraventriculares e ventriculares, relacionando-se com o momento de aparecimento e desaparecimento.

\section{VI.3 - Interpretação}

- Sinais e sintomas relatados e/ou identificados.

- Capacidade funcional e condição aeróbia, expressos em termos absolutos e comparativos em relação ao previsto para idade e sexo.

- Variáveis hemodinâmicas, destacando-se o comportamento da FC, PAS, PAD e do duplo produto. A análise deve ser feita durante o esforço e no período de recuperação.

- Traçados eletrocardiográficos, comparando os achados de repouso e esforço. Devem ser incluídos traçados representativos.

\section{VI.4 - Conclusões}

Comentário sumário enfatizando potenciais limitações do teste, procurando subsidiar as decisões clínicas aos principais achados do exame. Se possível, deve-se evitar as expressões genéricas, valorizando as informações de natureza epidemiológica, tais como o risco pré e pós teste e valor preditivo.

Conclusão final sobre teste positivo, negativo ou alterado.

Normal, limítrofe e anormal.

\section{Referências}

1. Consenso Nacional de Ergometria. Arq Bras Cardiol 1995; 65(Supl 2 ??): 1.

2. Balady GJ, Ades PA, Comoss P, et al. Core components of cardiac rehabilitation/ secondary prevention programs. Circulation 2000; 102: 1069-73.

3. American College of Sports Medicine. ACSM's Guidelines for Exercise Testing and Prescription, $6^{\text {th }}$ edition. Philadelphia: Lippincott Williams \& Wilkins, 2000.

4. Chaitman BR. Exercise stress testing. In: Braunwald E. Heart disease. $5^{\text {th }}$ ed. Philadelphia: WB Saunders, 2000.

5. Gibbons RJ, Balady GJ, Beasley JW, et al. American College Cardiology/ American Heart Association. Guidelines for exercise testing. J Am Coll Cardiol 1997; 30: 260-315.

6. Diamond GA, Forrester JS. Analysis of probability as an aid in the clinical diagnosis of coronary artery disease. N Engl J Med 1979, 300: 1350-8.

7. Diamond GA. A clinical relevant classification of the chest disconmfort. J Am Coll Cardiol 1983; 1: 574-5.

8. Detrano R, Gianrossi R, Froelicher V. The diagnostic accuracy of the exercise eletrocardiogram: a meta-analysis of 22 years of research Prog Cardiovasc Dis 1989; 32): 173-206

9. Gianrossi R, Detrano R, Mulvihill D, et al. Exercise-induced ST depression in the diagnosis of coronary artery disease: a meta-analysis. Circulation 1989; 80: 87-98.

10. Ladenheim ML, Kotler TS, Pollock BH, Berman DS, Diamond GA. Incremental prognostic power of clinical history, exercise electrocardiography, and myocardial perfusion scintigraphy in suspected coronary artery disease. Am J Cardiol 1987; 59: 270-7.

11. Ellestad MH, Wan MK. Predictive implications of stress testing. Follow-up of 2700 subjects after maximum treadmill stress testing. Circulation 1975; 51: 363 9.

12. Moreno R, Cantalpiedra JL, As EL, et al. Determinants of a positive exercise test in patients admitted with non-infarct chest pain. Int J Cardiol 1998; 66: 147-51.

13. Allen WH, Aronow WS, Goodman P, et al. Five year of follow-up of maximal treadmill exercise stress test in asymptomatic men and women. Circulation 1980; 62: 522-31.

14. Brunelli C, Cristofani R, L'Abbate A. Long-term survival in medically Treated patients with ischaemic heart disease and prognostic importance of clinical and electrocardiographic data (the Italian CNR Multicentre Prospective Study OD1). Eur Heart J. 1989; 10: 292-303.

15. Volpi A, de Vita C, Franzosi MG, et al. Predictors of nonfatal reinfarction in survivors of myocardial infarction after thrombolysis: results of the Gruppo Italiano per lo Studio della Sopravvivenza nell' Infarto Miocardico (GISSI-2) Data Base. J Am Coll Cardiol. 1994; 24: 608-15.

16. $26^{\text {th }}$ Bethesda Conference: Recommendations for determining eligibility for competition in athletes with cardiovascular abnormalities. Med Sci Sports Exerc 1994; 26(10 suppl): S223-83.

17. Ades PA. Preventing sudden death: cardiovascular screening of young athletes. Phys Sportsmed 1992; 20: 75-89.

18. Froelicher VF, Yanourtz FB, Thompson AJ, Lancaster MC. The correlation of coronary angiography and the electrocardiographic response to maximal treadmill testing in 76 asymptomatic men. Circulation 1973; 48: 597-604.

19. Abbott JA, Hiirschfeld DS, Kunkel FW, Scheinman MM. Graded exercise testing in patients with sinus node dysfunction. Am J Cardiol 1977; 62: 330-8.

20. James FW, Schartz Dc, Kaplan S, Spilkin SP. Exercise electrocardiogram,blood pressure, and working capacity in young patients with valvular or subvalvular aortic stenosis. Am J Cardiol 1982; 50: 769-75.

21. Alpert BS, Kartodihardjo W, Harp H, Izukawa T, Strong WB. Exercise blood pressure response: a predictor of severity of aortic stenosis in children. $\mathrm{J}$ Pediatric 1981; 98: 763-5.

22. Areskog NH. Exercise testing in the evaluation of patients with valvular aortic stenosis. Clin Phisiol 1984; 4; 201-8.

23. Hochreiter C, Borer JS. Exercise testing in patients with aortic and mitral valve disease: current applications. Cardiovasc Clin 1983; 13: 291-300.

24. Fleg JL, Piña IL, Balady GJ, et al. Assessment of functional capacity in clinical and research applications: an advisory from the Committee on Exercise, Rehabilitation, and Prevention, Council on Clinical Cardiology, American Heart Association. Circulation 2000; 102: 1591-7.

25. Davies LC, Francis DP, Piepoli M, Scott AC, Ponikowski P, Coats AJS. Chronic heart failure in the elderly: value of cardiopulmonary exercise testing in risk stratification. Heart 2000; 83: 147-51. 
26. Myers J, Gullestad L, Vagelos R, et al. Cardiopulmonary exercise testing and prognosis in severe heart failure: $14 \mathrm{~mL} / \mathrm{kg} / \mathrm{min}$ revisited. Am Heart J 2000; 139: 78-84.

27. Fontaine JM. Evaluation of patients with complex ventricular arrhytmias: current noninvasive and invasive methods. Am Heart J 1992; 123: 1123-9.

28. Couniham PJ, Frenneaux MP, Webb DJ, McKenna WJ. Abnormal vascular responses to supine exercise in hypertrophic cardiomyopathy. Circulation 1991; 84: 686-96.

29. Jouven X, Zureik M, Desnos M, Courbon D, Ducimetière P. long-term outcome in asymptomatic men with exercise-induced premature ventricular depolarizations. N Engl J Med 2000; 343: 826-33.

30. Oliveira Jr WO, Toscano AC, Coutinho R, Monteiro MF. Análise crítica das arritmias induzidas pelo TE. Arq Bras Cardiol 1984; 43: 371-6.

31. Podrid PJ, Venditti FJ, Levine PA, Klein MD. The role of exercise testing in evaluation of arrhythmias. Am J Cardiol 1988; 62: 24H-33H.

32. Allen BJ, Casey TP, Brodsky MA, Luckett CR, Henry WL. Exercise testing in patients with life-threatening ventricular tachyarrhythimias: results and correlation with clinical and arrhythmia factors. Am Heart J 1988; 116: 997 1002.

33. Califf RM, McKinnis RA, McNeer JF, et al. Prognostic value of ventricular arrhythmias associated with treadmill exercise testing in patients studied with cardiac catheterization for suspected ischemic heart disease. J Am Coll Cardiol 1983; 2: 1060-7.

34. Gazes PC. False positive exercise testing the presence of Wolf-Parkinson-White syndrome Am Heart J 1969; 78; 13-8

35. Atwood JE, Myers J, Sullivan M, et al. Maximal exercise testing and gas exchange in patients chronic atrial fibrillation. J Am Coll Cardiol 1988; 11; 508-13

36. Dreifus LS, Fisch C, Griffin JC, Gillette PC, Mason JW, Parsonnet V. ACC/AHA $>$ Guidelines of implantation of cardiac pacemakers and anti-arrhythmia devices. Circulation 1991; 84: 455-67.

37. Gatzoulis MA, Clark AL, Cullen S, Newman CG, Redington AN. Right ventricular diastolic function 15 to 35 years after repair of tetralogy of Fallot: restrictive physiology predicts superior exercise performance. Circulation 1995; 91: 1775-81.

38. Jones NL. Clinical Exercise Testing. Philadelphia: WB Saunders, $4^{\text {th }}$ edition, 1997.

39. Jones NL. Exercise limitation in health and disease. N Engl J Med 2000; 343 632-41.

40. Polanczyck CA, Johnson PA, Hartley LH, Walls RM, Shaykevich S, Lee TH Clinical correlates and prognostic significance of nearly negative exercise tolerance test in patients. Revista ? Vol ? Ano ? Pág.

41. Mikhail MG, Smith FA, Gray M, Britton C, Frederiksen SM. Cost-effectiveness of mandatory stress testing in chest pain center patients. Ann Emerg Med 1997; 29: 88-97.

42. Kerns JR, Shaub TF, Fontanarosa PB. Emergency cardiac stress tes in the evaluation of emergency department patients with atypical chest pain. Ann Emerg Med 1993; 22: 794-8.

43. Chaitman BR, McMahon RP, Terrin M, et al. Impact of treatment strategy on predischarge exercise test in the Thrombolysis in Myocardial Infarction (TIMI) II Trial. Am J Cardiol 1993; 71: 131-8.

44. Froelicher VF, Perdue S, Pexen W, Rissh M. Application of meta-analysis using an eletronic spread sheet for exercise testing in patients after myocardial infarction. Am J Med 1987; 83: 1045-54

45. Management of acute coronary syndromes: acute coronary sydromes without persistent ST segment elevation: Recommendations of the Task Force of the European Society of Cardiology. Eur Heart J 200; 21: 1406-32.

46. Nixon JV, Hillert MC, Shapiro W, Smitherman TC. Submaximal exercise testing after unstable angina. Am Heart J 1980; 99: 772-8.

47. Nyman I, Wallentin L, Areskog M, et al. Risk stratification by early exercise testing after an episode of unstable coronary artery disease: the RISK Study Group. Int J Cardiol 1993; 39: 131-42.

48. Specchia G, de Servi S, Falcone C, et al. Coronary arterial spasm as a cause of exercise-induced ST-Segment elevation in patients with variant angina. Circulation 1979; 59: 948-54.

49. Chaitman BR, Watera DD, Theroux P, Hansosn JS. S-T segment elevation and coronary spasm in response to exercise. Am J cardiol 1981: 47: 1350-8.

50. Lauer MS, Francis GS, Okin PM, Pashkow FJ, Snader CE, Marwick TH. Impaired chronotropic response to exercise stress testing as a predictor of mortality. JAMA $1999 ; 281 ; 524-9$.

51. Lauer MS, Okin PM, Larson MG, Evans JC, Levy D. Impaired heart rate response to graded exercise: prognostic implications of chronotropic incompetence in the Framingham heart Study. Circulation 1996; 93: 1520-6.

52. Cole CR, Blackstone EH, Pashkow FJ, Snaider CE, Lauer MS. Heart rate recovery immediately after exercise as a predictor of mortality. N Engl J Med 1999; 341; 1351-7.

53. Cole CR, Foody JM, Blackstone EH, Lauer MS. Heart rate recovery after submaximal exercise testing as a predictor of mortality in a cardiovascular healthy cohort. Ann Intern Med 2000; 132: 552-5.

54. McHam AS, Marwick TH, Pashkow FJ, et al. Delayed systolic blood pressure recovery after graded exercise: na independent correlate of angiographic coronary disease J Am Coll Cardiol 1999; 34: 754-9.

55. Lavie CJ, Oh JK, Gibbons RJ, et al. Significance of T-wave pseudo-normalization during exercise: A radionuclide angiographic study. Chest 1988; 94: 512-6.

56. Madsen JK, Stubgaard M, Utne HE, et al. prognosis and thallium-201 scintigraphy in patients admitted with chest pain without confirmed myocardial infarction Br Heart J 1988; 59: 184-9.

57. Freeman MR, Chisolm RJ, Armstrong PW. Usefulness of exercise electrocardiography and thallium scintigraphy in unstable angina pectoris in predicting the extent and severity of coronary artery disease. Am J Cardiol 1988: 62: 1164-70.

58. Margonato A, Ballarotto C, Bonetti F, et al. Assessment of residual tissue viability by exercise testing in recent myocardial infarction: comparison of the electrocardiogram and myocardial perfusion scintigraphy. J Am Coll Cardiol 1992; 19: 948-52.

59. Lombardo A, Loperfido F, Pennestri F, et al. Significance of transient ST-T segment changes during dobutamine testing in Q wave myocardial infarction. $\mathrm{J}$ Am Coll Cardiol 1995; 27: 599-605.

60. Lin SS, Lauer MS, Marvick TH. Risk stratification of patients with medically treated unstable angina using exercise echocardiography. Am J Cardiol 1998; 82: $720-4$

61. Wasserman K, Sue DY. Cardiovascular coupling of external to cellular respiration. In: Wasserman K. Exercise Gas Exchange in Heart Disease. Armonk: Futura, 1996: 1-16. 


\section{Siglas utilizadas neste documento}

\begin{tabular}{|c|c|}
\hline $\mathrm{ACC}$ & American College of Cardiology \\
\hline AHA & American Heart Association \\
\hline ATC & Angioplastia transluminal coronariana \\
\hline bpm & batimentos por minuto \\
\hline BAV & bloqueio atrioventricular \\
\hline BAVT & bloqueio atrioventricular total \\
\hline BRD & bloqueio de ramo direito \\
\hline BRE & bloqueio de ramo esquerdo \\
\hline CATE & cateterismo cardíaco \\
\hline CRM & cirurgia de revascularização do miocárdio \\
\hline DAC & doença arterial coronariana \\
\hline DERC & DepartamentodeErgometriaeReabilitaçãoCardíaca \\
\hline ECG & eletrocardiograma \\
\hline ECO & ecocardiograma \\
\hline FA & fibrilação atrial \\
\hline FC & freqüência cardíaca \\
\hline HAS & hipertensão arterial sistêmica \\
\hline HVE & hipertrofia ventricular esquerda \\
\hline IAM & infarto agudo do miocárdio \\
\hline IC & insuficiência cardíaca \\
\hline ICC & insuficiência cardíaca congestiva \\
\hline IVE & insuficiência ventricular esquerda \\
\hline MAPA & monitorização ambulatorial de pressão arterial \\
\hline MET & equivalente metabólico \\
\hline MP & marcapasso artificial \\
\hline NYHA & New York Heart Association \\
\hline PA & pressão arterial \\
\hline PAD & pressão arterial diastólica \\
\hline PAS & pressão arterial sistólica \\
\hline PCR & parada cardiorrespiratória \\
\hline SBC & Sociedade Brasileira de Cardiologia \\
\hline TE & teste ergométrico \\
\hline TSV & taquicardia supraventricular \\
\hline TV & taquicardia ventricular \\
\hline & consumo de oxigênio corpóreo \\
\hline WPW & Wolff-Parkinson-White \\
\hline
\end{tabular}

